\title{
A ImportânCIA do ConHECIMENTO TÁcITO EM QUímIICA um tributo a Alberto Romão Dias
}

\author{
Sebastião J. Formosinho*
}

No primeiro dia da $7^{a}$ Conferência de Química Inorgânica da Sociedade Portuguesa de Química (Fátima de 30 de Novembro a 1 de Dezembro de 2007) teve lugar uma sessão de homenagem ao nosso saudoso colega Prof. Alberto Romão Dias. A sessão "Remembering Romão Dias" foi presidida e coordenada pelo seu primeiro filho-científico, o Prof. Carlos Romão. A Profa Ana Margarida Martins, sua neta-científica, na comunicação intitulada "Highlights on Organometallic Chemistry in Romão Dias Group", afirmou, com grande ênfase, que para a síntese de alguns dos compostos com que trabalham os membros do grupo são insuficientes as "receitas". Requer-se uma aprendizagem com quem os sabe fazer. Um exemplo bem claro de conhecimento tácito em química, um conhecimento que não se consegue exprimir plenamente por palavras ou proposições mas requer uma acção para ser transmitido. Foi Michael Polanyi que criou este conceito, procurando contrariar a visão do positivismo de que todo o conhecimento científico é conhecimento explícito, articulável. Aliás, trata-se do maior contributo deste químico para a filosofia das ciências e para a teoria do conhecimento.

O mais surpreendente é que estando o conhecimento tácito tão presente em todas as formas do conhecimento e das realizações humanas esteja tão ignorado em todo o processo educativo. Polanyi está omisso numa obra recente e tão abrangente como "Nova Educação na Nova Ciência para a Nova Sociedade" de Duarte Costa Pereira [1]. E a falta não é do autor: o pensamento deste químico e filósofo húngaro não transitou para qualquer highlight da teoria do conhecimento.

Walter Gulick reivindica mesmo que este "conceito" requer ser incluído

Professor Catedrático de Química, Departamento de Química - Universidade de Coimbra

Rua Larga 3004-535 Coimbra

sformosinho@qui.uc.pt num sistema filosófico, para uma reflexão mais profunda e coerente [2]. Julgo que o Romão Dias, a quem a Sociedade Portuguesa de Química muito deve no seu rejuvenescimento, quer no domínio científico quer no campo do ensino básico e secundário, ficaria satisfeito que, ainda pela sua mão, esta temática fosse abordada com finalidades educativas, mesmo que de uma forma necessariamente resumida. Procurarei fazer o meu meIhor, para valorizar o tributo que pretendo prestar à sua memória.

\section{Arte ou CONHECIMENTO tÁcito EM QUÍMICA?}

Escrevi à Prof. Ana Martins o seguinte e-mail: "A Ana falou com grande ênfase que para a síntese de alguns dos compostos com que trabalham, são insuficientes as "receitas". Requer-se uma aprendizagem com quem os sabe fazer. Isto deu-me uma ideia, que lhe explicarei mais tarde para que ela não se vá reflectir de algum modo nas suas palavras. Venho pedir-lhe que a ideia central que me ficou deste seu início de intervenção pudesse ser escrita por si, sem a minha tradução das suas próprias ideias».

Respondeu-me de pronto, e a sua resposta podemos entendê-la como o "facto bruto", isento de qualquer revestimento da teoria do conhecimento tácito:

«A referência que fiz da necessidade de aprender com alguém que tivesse tido anteriormente a experiência de síntese de complexos di-hidreto de Mo e $W$, de fórmula geral $\mathrm{Cp}_{2} \mathrm{MH}_{2}$ que foram os compostos de partida para o estudo dos sistemas de Mo e $W$ da família dos metalocenos dobrados, aplica-se exclusivamente a estes compostos e resulta de circunstâncias particulares destas reacções que felizmente não são comuns a muitos complexos organometálicos. Estas são, de facto, reacções difíceis de levar a cabo.
A dificuldade em descrever a reacção prende-se não só com o facto de envolver uma sequência de passos que requer material específico (um forno adequado à síntese dos cloretos de Mo ou W, que têm que ser sublimados e arrastados pela corrente de $\mathrm{Cl}_{2}$ à medida que se vão formando para um recipiente em que estejam ao abrigo de ar e humidade, um agitador mecânico adequado para a síntese de $40 \mathrm{~g}$ de areia de sódio em $2 L$ de tolueno ao refluxo e para a agitação da mistura reaccional que é feita em $2 L$ de THF $a-80^{\circ} \mathrm{C}$ num balão de $3 \mathrm{~L} \mathrm{com} 3 \mathrm{tu}$ buladuras, filtros de grande dimensão para remover impurezas que podem ser poliméricas e difíceis de separar, etc.) mas também porque a grande escala em que a reacção tem que ser realizada envolve etapas que podem ser perigosas ou podem originar a decomposição de um intermediário reaccional, se realizadas por alguém que não tenha tido a experiência adequada. Ao longo dos vários passos reaccionais, as misturas têm frequentemente cores não definidas e viscosidades variáveis que determinam que os volumes de solventes usados nas várias extrações feitas ao longo da síntese variem, com consequências importantes no rendimento final da reacção. À data a que me estava a referir, e até há cerca de 10-15 anos atrás, estes complexos não eram comercializados (ainda hoje são bastante caros) e isso limitava significativamente a possibilidade de serem usados em estudos de síntese e reactividade, que necessitam em geral de quantidades significativas de reagentes. Resumindo, estas não são reacções em que seja possível descrever de modo inequívoco as cores, os tempos e outras variáveis que permitam que quem as realiza pela primeira vez se sinta confortável e seguro de que vai obter qualquer resultado no fim da semana de trabalho intensivo que exigem.

A possibilidade que tivemos de estudar de forma bastante extensa a química destes complexos resultou do facto de o Romão Dias 
ter feito o seu doutoramento em Oxford com o Malcolm Green, que foi quem desenvolveu o procedimento de síntese destes complexos (enquanto estudante de doutoramento de Wilkinson). Este aspecto é claro quando se vê o percurso académico daqueles que estudaram estes sistemas: todos eles passaram pelos grupos de Wilkinson ou Malcolm Green.

Espero ter conseguido esclarecer o intuito da menção que fiz, que tinha como objectivo contextualizar o trabalho de investigação em química organometálica que foi a origem do Grupo do Romão Dias. Fico curiosa em relação à ideia que isto possa ter suscitado».

Esta prática tácita, mas consciente, da química de síntese é, como veremos, conhecimento científico. No contexto da visão oriunda do positivismo para as ciências da natureza, de um conhecimento científico inteiramente explícito e cerzido com a linguagem, este modo de conhecimento é assumido, em palavras do Carlos Romão, "como do domínio "artístico", ou seja, aprender/ensinar "à vista" ou aprender fazendo por imitação» .

Em 1959, o novelista e químico-físico inglês C. P. Snow publicou um escrito que ficou famoso: "As Duas Culturas". Por formação um cientista, e por vocação um escritor, Snow apercebeu-se da existência de dois mundos culturais representados por dois grupos de intelectuais, com gente igualmente inteligente, mas tendo cessado de comunicar entre si. Adiantando um pouco o nosso propósito, este fosso entre as duas culturas é artificial, pois quem percorrer a história das ciências, mormente no que diz respeito à heterodoxia científica, encontra um paralelismo entre a cultura científica e a artística. Fernando Pessoa escreveu: «Todo o autor, na proporção em que é grande e ao mesmo tempo original, tem tido sempre que criar o sentido estético pelo qual há-de ser apreciado; assim foi sempre e assim continuará a ser ...» [3]. O mesmo é muitas vezes válido em ciência, não para um sentido estético mas cognitivo, nomeadamente quando a inovação científica procura estabelecer novas regras para explicar alguma fracção do mundo e dos seus fenómenos.

Mas admitamos que esta prática de síntese química tem uma componente artística. E de que tipo de arte? Se escolhermos uma arte musical, não se pode assemelhar ao jazz que herdou principalmente o caráter espontâneo e de improviso. A síntese química pretende obter um resultado reprodutível e com um rendimento elevado e constante. Talvez uma peça musical de piano seja mais apropriado como modelo, algo como uma obra prima de Mozart, o Concerto No. 9 em Mi Bemol Maior, K271.

Tocar piano, tal como andar de bicicleta ou nadar, são actividades que funcionam sobre um fundo inarticulável enquanto tais actividades estão a ser praticadas. Tal não implica que, uma vez cessada a sua prática, o praticante não as consiga verbalizar e criticar. Mas o cerne da mensagem é que «sabemos mais do que conseguimos dizer».

Sem dúvida podemos «Pensar a ciência como arte», como o faz Ernst Peter Fischer [4], ou ver "as artes como ciências", recorrendo, a título exemplificativo, a teorias cognitivas para estudos literários ou de história, como sugere Peter Hanenberg. Deste modo evita-se a «separação herdada entre as ciências naturais e as ciências humanas». Retomaremos esta problemática.

Mas adiantando, mais uma vez, o conto da nossa história, direi que a Teoria do Conhecimento Tácito (TCT) é mais profunda na essência dos nossos modos de conhecer e de construir o conhecimento como seres vivos. É pois dos domínios do epistemológico e do antropológico e, direi mesmo, do ontológico.

\section{OS PRIMÓRDIOS DO CONHECIMENTO tácito em Michael Polany}

Michael Polanyi desenvolveu o conceito de tacit dimension nas obras Personal Knowledge [5] e The Tacit Dimension [6], conceito que posteriormente designou por «conhecimento tácito»: «it is one of the most striking abilities of the human mind that it can pursue a consistent course of action without being aware of the guiding principles involved» [7]. E a este respeito ilustra o conceito com exemplos oriundos da gramática, de práticas de artes e ofícios, de máximas de métodos científicos, de intuições criativas de descobertas. As práticas químicas que a Prof. ${ }^{a}$ Ana Margarida Martins referiu para a síntese de $\mathrm{Cp}_{2} \mathrm{MH}_{2}$ também podem figurar como um "exemplo forte" destes modos de conhecimento tácito.

Como referi na minha Oração de Sapiência de 19 de Setembro de 2007 ("Pensar e Olhar a Ciência") [8], Polanyi vai mais longe no seu entendimento sobre o conhecimento tácito. Não é apenas o conhecimento que requer uma acção para ser transmitido - digamos uma articulação mediante a acção numa relação de mestre e aprendiz - que tem um carácter tácito. O conhecimento tácito está presente na própria vida animal e, por definição, este tipo de inteligência pré-linguagem é plenamente tácito. Um exemplo bem ilustrativo neste campo foi por mim apresentado em obra recente [9].

No ser humano, a distinção crucial entre conhecimento explícito e conhecimento tácito assenta precisamente na impossibilidade de uma articulação verbal. Não conseguimos descrever por palavras como reconhecemos certos cheiros e sabores, como o cheiro do café, ou descortinamos uma fisionomia conhecida entre algumas centenas de pessoas, ou como praticamos certas artes manuais, ofícios e técnicas que se transmitem pela acção e se aperfeiçoam pela prática.

Apesar de o conhecimento tácito ser fruto de um acto consciente, não é inteiramente verbalizável, como o tocar piano. Não obstante, distingue-se dos processos tácitos que são largamente não-conscientes [10], uma via inferior que funciona em automático, fora da nossa consciência e a grande velocidade.

A linguagem expandiu a inteligência humana para além do domínio do conhecimento tácito, e converteu-se em 
instrumento que o homem utiliza para conhecer o mundo, mas a aplicação racional de um tal instrumento é sempre fruto do empenho e do desempenho pessoal. A raiz do conhecimento na pessoa humana, entende Polanyi ser a mesma que leva um ratinho a encontrar a saída de um labirinto. É uma actividade tácita e é sobre este fundo que todo o conhecimento humano, mesmo o explícito, consegue estabelecer um contacto com o mundo. Digamos que a linguagem é parasita de material tácito que cada um foi integrando na sua memória de longo prazo, quer na estrutura semântica quer na episódica.

Letras, símbolos matemáticos são informação, mas não conferem sentido e significado a essa mesma informação. É a pessoa, com o seu fundo de conhecimento tácito, a prestar um sentido à informação e a conferir-lhe características de conhecimento explícito. Assim sendo, toda a forma de conhecimento ou é tácita ou está enraízada num conhecimento que é tácito - «all knowledge is either tacit or rooted in tacit knowledge» [11]. Esta enfâse na primazia no carácter tácito do conhecimento científico está diametralmente oposta à obsessão do positivismo, de que todo o conhecimento científico tem um carácter explícito.

Há que reconhecer, porém, em tudo isto, uma inevitável circularidade: a necessidade do uso de palavras para exprimir aquele tipo de conhecimento que não se consegue exprimir plenamente de forma verbal.

\section{A estrutura do CONHECIMENTO tácIto}

«Toda a focalização consciente num objecto ou num acontecimento depende da integração tácita de uma apreciável variedade de pormenores subsidiários em ordem a produzir um todo coerente». É precisamente a identificação deste dualismo focal-subsidiário que Walter Gulick identifica como a maior revolução que Michael Polanyi produziu nos domínios da Epistemologia [12].

Quando estamos conscientes de alguma coisa $(A)$ para atendermos a uma outra $(B)$, encontramo-nos conscientes de $A$ de uma forma subsidiária. $A$ entendidade $B$ que é o centro da nossa atenção focalizada, é que confere algum significado de coerência às entidades $A$, que podem ficar ou não por especificar. Os dois tipos de consciência excluem-se mutuamente. Quando desviamos a nossa atenção de algo $(A)$ de que estávamos a ter consciência de uma forma subsidiária para nele focalizarmos a nossa atenção consciente, o A perde o seu significado prévio, e podemos acabar por exercer um certo tipo de análise destrutiva.

Um bom exemplo para se examinar a estrutura do conhecimento tácito foi apresentado por Polanyi a respeito do uso de um «martelo para pregar um prego» [13]. Quando pregamos um prego estamos cientes do prego e também cientes do martelo e das sensações na palma da mão. Mas de um modo diferente: o prego estamos dele cientes de um modo focal, mais distante e mais central na nossa atenção, e do martelo e das mãos de um modo subsidiário, mais próximo e mais difuso, como pormenor. O conhecimento tácito constrói-se nesta relação dinâmica de estarmos cônscios de um modo focal e de um modo subsidiário, na fusão do subsidiário no focal; de outro modo, o sujeito do conhecimento era incapaz de exercer qualquer modo de acção devido a solicitações desencontradas. Para "agarrarmos" um objecto temos de integrar todas as pistas e sinais relevantes que nos chegam dele para formar um todo coerente.

É no acto de compreensão que meIhor se domina a estrutura da teoria do conhecimento de Polanyi, que é a TCT. Possui um carácter tácito o acto de procurarmos "agarrar" as partes separadas (os aspectos particulares ou subsidiários) num todo (focal) coerente e compreensivo. Haverá sempre uma fracção de "particulares" que permanecem inespecificados, mas, paralelamente, quando os particulares conseguem ser isolados e especificados de certo modo acabam por ser eles mesmos modificados neste acto de os delimitar. Porém, o objecto de que temos consciência focal encontra-se sempre especificado.
Como médico de formação universitária e de exercício como médico militar na $1^{\text {a }}$ Grande Guerra, Michael Polanyi ilustrou bem este tipo de dificuldade. É fácil identificar os diferentes orgãos num corpo humano, mas a relação mútua deles no interior do corpo requer um esforço sustentado de imaginação com base em aspectos parcelares, fruto dos sucessivos estádios de dissecção de um cadáver [14].

Quem articula o focal com o subsidiário é uma pessoa. As artes de conhecer e de fazer são estrututalmente afins e, de alguma forma, interligam-se entre si [15]. O conhecimento pessoal é uma fusão entre o pessoal e o universal, uma reivindicação para estabelecer contactos com uma realidade exterior à própria pessoa. E as capacidades pessoais para o acto de conhecer têm muito de tácito. Trata-se da corporalização do contacto com a realidade. Uma realidade que passa a habitar dentro de nós e com a qual "convivemos" (indwelling) e que nos leva a distribuir as nossas "afeições" pelos diferentes pormenores que carecem de ser coordenados num todo.

As coisas que podemos verbalizar conhecemo-las por observação (focal), as que não conseguimos verbalizar, por serem subsidiárias, conhecemo-las por "convivermos" com elas (um dwelling sobre elas), formando um fundo de entendimento para o qual as palavras não são necessárias; são interiorizadas e "habitam" na nossa memória de longa duração [16].

É relevante distinguir entre o conhecimento tácito passivo que funciona sobre um fundo de indwelling, do conhecimento tácito activo, como o que adquirimos quando aprendemos a tocar piano, aprendemos a ler mapas, ou a "lançar" no basquetebol. As práticas de síntese química $\mathrm{Cp}_{2} \mathrm{MH}_{2}$ descritas por Ana Martins são práticas conscientes adquiridas na relação entre mestre e aprendiz, e são, por conseguinte, conhecimento tácito. Mas cada praticante deste tipo de sínteses também funciona mediante processos tácitos inconscientes, como os de coordenação muscular, visual e táctil. 


\section{O VALOR DO INEXACTO}

Polanyi escreveu um pequeno escrito que intitulou o valor do inexacto onde afirmou: "The subject of chemical concepts as opposed to physical ones has always been fascinating to me because it shows the great value of inexact ideas»[17]. Para mais à frente acrescentar: "os químicos andaram bem em não se deixarem atemorizar pelos físicos no desiderato de só buscarem "leis exactas", que parece ser o campo predilecto da Física. Se a Química só tivesse procurado estabelecer "leis exactas", o seu desenvolvimento e progresso teriam sido de alcance muito diminuto. Procurem ligar dois átomos a um terceiro [um problema de 3-corpos]; o comportamento do sistema é tão complexo que fica para bem longe da "exactidão física"». E, no entanto, representa o paradigma da transformação microscópica em química. A química é um mundo de ideias onde conceitos como «afinidade», «estabilidade relativa», "tendências», etc. são aceites como modos de tradução de certas formas de comportamento químico.

Michael Polanyi trouxe um novo modo cêntrico para organizarmos o conhecimento. Nas ciências cognitivas entende-se que é o conflito cognitivo o motor do desenvolvimento do conhecimento humano. Mas a Teoria do Conhecimento vem mostrar que todo o conhecimento explícito foi antecedido por alguma vaga noção de uma intuição racional, que carece posteriormente de ser defendida pelo sujeito deste novo conhecimento com convicção pessoal. A força motriz do nosso conhecimento são pois noções vagas e incertas e não conceitos precisos e explícitos como as teorias do conhecimento têm vido a propor e que, de alguma forma, mesmo os psicólogos do desenvolvimento não prestam a devida atenção [18].

Aliás este químico húngaro vai mais longe no seu pensamento, após ter tomado contacto com a "Introdução à Lógica" de Tarski e com o teorema de Gödel, ao concluir: «every logical proof must ultimately have to rely on intuition» [19], ou em palavras ainda mais fortes, «our deepest convictions lack all theoretical foundation» [20].
Neste contexto, Blythe Clinchy advoga que os professores devem também actuar como "pares" perantes os seus educandos, permitindo que exprimam indecisões e incertezas na formação do seu conhecimento, porque polanyianamente «sabem mais do que conseguem dizer». Se assim actuarem, as crianças tornam-se mais criativas e independentes. Tal é particularmente apropriado no ensino das artes, porque não há um modo único, certo e exacto de abordarmos um sentido estético. O que é relevante é que os estudantes assumam uma dada posição e a saibam defender (o porquê?) perante outros [21]. Tal evita que o estudante caia numa posição de subjectivismo, em que as convicções sejam válidas só para o próprio, num relativismo extremo.

Em Polanyi o conhecimento pessoal tem uma motivação de "universal" o que, sem impedir o envolvimento activo do sujeito na construção do seu conhecimento, aponta para uma universalidade que subtrai o sujeito do conhecimento a uma posição de subjectivismo [22]. A noção do conhecimento pessoal e indwelling em Polanyi tem profundas semelhanças com a mais recente noção de conhecimento interligado (connected knowing) da psicóloga do desenvolvimento Blythe Clinchy [23].

A um nível mais geral, o objectivo assenta mais em as crianças procurarem fazer sentido das noções cognitivas que desenvolvem do que em verificar a validade de tais noções. Tal assenta na criação de climas de convivialidade nos quais os estudantes se sentem livres em partilhar os seus processos de aquisição de conhecimento. Um modo colaborativo de aquisição de conhecimento; o objectivo dos estudantes é mostrar o que sabem aos seus professores e não, por parte destes, o procurarem determinar o que os estudantes não sabem. Tudo tem o seu lugar, mas agora o que carece de ser fomentado, por dele carecer o processo educativo, é algum clima de convivialidade cognitiva.

O acto da descoberta é particularmente rico para o processo de formação de conhecimento mesmo em jovens estudantes, como o mostra
Clinchy em estudos de psicologia do desenvolvimento. Um problema que não suscita uma intimação pessoal, não existe como problema. E no acto de intimação, o sujeito ainda vê fragmentos de conceitos e fenómenos dispersos e sem sentido. As imagens mentais que se formam são imagens de circularidade e não imagens lineares de um percurso simples da confusão para o todo coerente. A mente circula à volta do todo coerente, em círculos cada vez mais apertados, e que vão filtrando a informação dispersa, sem que disso se aperceba o estudante, até que num flash emerge o sentido coerente da informação com que estava a lidar [24]. A partir deste momento, o estudante adquire auto-confiança, apesar de não ter a certeza da validade do conhecimento que assim conseguiu construir.

Neste enquadramento não surpreende que Polanyi tenha reconhecido bem cedo que toda a descoberta científica teve origem em algum problema vago (ainda incapaz de formulação) mas que vai actuar como o foco de coerência de todo um outro conjunto de pormenores.

Uma noção central para um melhor entendimento do conhecimento tácito faz apelo a esquemas gerais (gestalt) para processamento mental da informação, que funcionam como "mapas" ou "modelos" mentais e que proporcionam às pessoas expectativas sobre o que pode vir a acontecer com base em experiências passadas. Tais esquemas processam a informação de um modo heurístico e não algorítmico. Robert Howard admite que tais esquemas, muito gerais, são usados amplamente na percepção, na compreensão, na aprendizagem, na memorização e na resolução de problemas [25].

Polanyi considera três tipos de conhecimento tácito nos animais: i) tricklearning (aprendizagem por recurso a truques) que conduz a aprendizagem por desenvolvimento de um padrão de «memória para procedimento», como se verifica em animais na busca de alimento; um rato consegue mover-se num labirinto que na saída tenha a comida que ele pretende; ii) signallearning (aprendizagem por reco- 
nhecimento de sinais) que conduz a aprendizagem por desenvolvimento de um padrão de «memória para representação de percepções», como quando animais reconhecem sinais para acasalamento ou de reacções de medo noutros animais; iii) latent-learning (aprendizagem latente) que conduz a aprendizagem por desenvolvimento de um padrão de abertura de novos caminhos na memória semântica, na busca de soluções alternativas se as soluções de rotina se encontram bloqueadas [26].

Como os "esquemas" ou "modelos" mentais acima referidos são adquiridos graças a um grande esforço pessoal, são o verdadeiro armazém das verdades pessoais duramente conquistadas que cada um defende e pelas quais luta, na convicção que, como referimos, possuem uma validade universal.

Como seres humanos não estamos situados «nenhures» ou em «todos os tempos e lugares» para ajuizar dos méritos das nossas racionalidades e valores, e demonstrar de modo irrefutável a sua verdade. Estamos situados num tempo e numa cultura e é a partir daí que fazemos juízos e adquirimos o nosso conhecimento pessoal [27].

A participação pessoal do sujeito do conhecimento no conhecimento em que ele próprio acredita não tem pois um fundamento lógico, mas psicológico: implica um sentimento de paixão. E ficar atormentado por um problema é estar convicto ter esse problema uma solução, e alegrar-se com a descoberta da solução é aceitar que ela é verdadeira, mesmo sabendo poder estar errada [28]. Como o conhecimento pessoal é guiado por este tipo de paixão humana não é inteiramente objectivo, mas ao estarmos convictos da sua universalidade também não é inteiramente subjectivo [29].

Neste modo teórico de pensamento, «como podemos conhecer os objectos que nos são exteriores, se a nossa consciência deles é sempre interna?». A resposta polanyiana baseia-se numa correcta compreensão da dimensão tácita do nosso contacto com a realidade. O nosso corpo é como se fosse o instrumento do duplo contacto com a realidade, porque participa plenamente na vida da nossa mente e contacta mediante os orgãos sensoriais com a realidade exterior. Convivemos (dwelling) na nossa memória interior com a realidade a que pretendemos prestar atenção e explorar, distribuindo o consciencial pelo focal e pelas facetas subsidiárias [30]. A corporalização tácita faz essa transição da realidade exterior para o interior mental.

\section{O PAPEL DO CONHECIMENTO TÁCITO EM EDUCAÇÃO}

O conhecimento tácito está presente em todos os processos de aprendizagem e de realização humana, pelo que é central ao processo educativo, apesar de muito ignorado. É vital conhecermos as raízes deste modo de conhecimento, para melhor o desenvolvermos. Outro contributo importante da TCT em qualquer projecto educativo é corrigir a visão de uma falsa objectividade para o conhecimento científico que o positivismo trouxe à humanidade, assumindo-nos como robots insencientes. Quer o positivismo quer o cientismo são filosofias que rejeitam os processos e o conhecimento tácitos como subjectivos e pouco credíveis, tendo-nos arrastado para uma ciência desumanizada e abissalmente distante das ciências do homem e da sociedade e, inevitavelmente, da religião. $E$, no entanto, a nossa própria linguagem depende vitalmente de processos e conhecimentos tácitos. Se observamos um objecto para o conhecermos, evocamos palavras e conseguimos descrevê-lo; mas se "convivermos" com as facetas subsidiárias, elas figuram num fundo de entendimento para o qual não são requeridas palavras [31].

Na perspectiva de Polanyi, dado que os métodos da inquirição científica não conseguem ser formulados plenamente de um modo explícito, carecem de ser transmitidos como se de uma arte se tratasse, através da afiliação de um discípulo a um mestre [32]. Daí o papel da tradição - o que vale a pena preservar e ser transmitido entre gerações - em ciência, mas de uma tradição tácita transmitida através de uma relação de autoridade criada entre o mestre e o aprendiz; «uma autoridade que cultiva a originalidade» [33], e uma originalidade que tenha uma função. Uma tal aprendizagem requer uma associação pessoal do aprendiz aos seus mestres, quer no pensamento quer nas práticas científicas. Nada melhor para ilustrar este papel da tradição em ciência que atentarmos na "Genealogia Científica de Alberto Romão Dias (1970-2007)" que tão gentilmente o meu colega Carlos Romão me cedeu para este efeito.

Tudo isto ilustra o papel e a importância da formação e preservação de escolas mesmo nos domínios das ciências da natureza, problemática a que a Universidade Portuguesa dos nossos dias parece tão alheia, mormente no tocante à renovação geracional. Mas comecemos por exemplos paradigmáticos, mais próximos do campo das artes.

Não obstante os enormes progressos científicos e tecnológicos dos últimos 300 anos e com os correspondentes poderosos meios de análise física e química, não se conseguiu recuperar a tradição artesanal do fabrico de instrumentos de corda, violinos e violoncelos, de Antonio Stradivari, os famosos stradivarius, de que existem ainda mais de 600 instrumentos em todo o mundo, mas apenas seis deles com a resina que the deram a fama pela pureza e riqueza dos sons que produziam, muitos deles mesmo inaudíveis ao ouvido humano. Quando se rompe a cadeia de transmissão de mestre a aprendiz, corre-se o risco de perder por completo toda uma tradição relevante, como este caso bem patenteia.

O filósofo Karl Popper, quando ainda professor na Nova Zelândia, chamou a atenção para o carácter local de algumas tradições, difíceis de transpor facilmente entre comunidades. Ao tempo teria mandado vir dos Estados Unidos uns discos de música de Mozart. O maestro que havia dirigido a orquestra durante as gravações não devia ter sido exposto a uma tradição mozartiana, pelo que a música soou 
horrivelmente a Popper. Uma pauta musical - uma tradição explícita não basta! Carece-se de uma tradição tácita transmitida através de uma relação entre mestre e aprendiz. Mas dado o papel que Popper atribuiu às teorias científicas [34], permaneceu inexplicado o carácter local e não universal das tradições científicas.

Nos domínios das ciências "exactas", atentemos no caso da estrutura de raios-X: «all structures are equal from their coordinates, but some structures are more equal than others!» [35]. E os autores procuram justificar a sua afirmação do frontispício nos seguintes termos: "The availability of X-ray derived structural information on proteinligand complexes is increasing, and this is a useful tool in lead optimization. However, the ambiguities associated with structural models derived from $X$ -ray data may not be fully appreciated. The process of deriving an atomic model from electron density data disguises uncertainties in the identity and position of ligand, water, and protein atoms. The observed ligand and protein conformation can be affected by crystallization conditions. It can be difficult for even the most conscientious medicinal chemist to avoid drawing misleading conclusions». Também nestes domínios há facetas de inexactidão que o conhecimento pessoal, habitante no seio de uma boa escola científica, consegue suplantar.

$\mathrm{Na}$ perspectiva da preservação de tradições de conhecimento científico, Michael Polanyi foi bem mais longe do que Karl Popper, pois não se confinou às tradições das hipóteses e teorias científicas; abordou também a arte da transmissão da própria investigação científica e, deste modo, é fácil entender o carácter local de uma tradição científica. Ao requerer uma aprendizagem de mestre e aprendiz, inevitavelmente é lenta a sua difusão. Resumindo: «A tradição explícita é global; a tradição tácita é local» [36].

A tradição da síntese dos compostos $\mathrm{Cp}_{2} \mathrm{MH}_{2}$ possui também este tipo de carácter local que, como acima referimos, se reconhece bem na genealogia científica de Malcom Green, Alberto Romão Dias, Carlos Romão e outros discípulos.
Há, porém, uma outra ordem de razões para relevar o papel da química no processo educativo. O de contribuir para superar o fosso entre as ciências da natureza e as humanidades e, consequentemente, a incomensurabilidade entre certas formas de vida, e as incoerências que a aceitação de tais filosofias têm acarretado ao mundo [37]. Mesmo sem recorrermos ao apelo de uma Terceira Cultura [38].

\section{SuPERAR O DISTANCIAMENTO ENTRE CIÊNCIAS DA NATUREZA E HUMANIDADES}

O positivismo surgiu como desenvolvimento filosófico do chamado "Século das Luzes", movimento que enfatizou a razão e a ciência como formas de explicar o universo. O positivismo é muito um fruto de se ter erguido a Física como parte principal da Filosofia. A Física é uma ciência altamente matematizada e de grande carácter abstracto. Isto é necessário neste tipo de ciência, que carece de tempo para especular e confontar as suas especulações com experiências complicadas, com observações astronómicas ou, nos nossos dias, com recolha de informações no espaço através de sondas. Mas contrasta com o modo de funcionamento de uma ciência irmã mais nova, a Química, que ao fugir das "leis exactas", está mais próxima dos fenómenos e mais algemada pelo confronto amíude com a experimentação laboratorial, não permitindo "flutuações" tão longe do homem e da sociedade como as da Física.

Claro que o sucesso da mecânica galilaica e newtoniana, muito fomentou esta perspectiva de desumanização das ciências. O progresso e a iluminação que as mesmas ciências trouxeram à humanidade, acabaram por desembocar também em práticas de contra-luz: a «inversão moral» nos regimes totalitários que assolaram o mundo ocidental no século $X X$ [39]. Esperava-se que as práticas de «matar em nome de Deus», notórias durante a Idade Média, evoluíssem de outro modo e cessassem. Mas quer no passado quer no presente, tais inversões sempre esqueceram o Homem e, muitas vezes, foi invocada e usada a Ciência para as jus- tificar, pois pareciam decorrer de "leis naturais da sociedade".

Neste contexto histórico de desumanização das ciências da natureza não admira que se tenha gerado um fosso entre estas e as humanidades como C. P. Snow bem atentou na sua famosa conferência sobre "As Duas Culturas".

Mas preservar um certo modo de produzir conhecimento sobre o mundo - a essência de uma qualquer tradição - é um acto da razão, uma escolha tão válida como um acto revolucionário ou de renovação [40]. A transmissão de uma tradição científica na sua componente explícita ou articulável de proposições só se torna efectiva e eficaz quando inserida na componente não-articulável da tradição científica - as capacidades e aptidões para levar a cabo a investigação científica e para reconhecer problemas relevantes, as intuições de criatividade que conduzem às descobertas e inovações, bem como o etos das comunidades científicas, que abarca uma forte componente ética de honestidade intelectual e de um amor à procura e à defesa da verdade ou daquilo que se julga como tal, uma adesão à veracidade.

Com efeito, mesmo nas ciências da física encontramos sinais da presença da componente tácita na feitura desta ciência, nas suas tradições científicas. Por exemplo, a existência de famílias científicas de Prémios Nobel da Física, como Compton, Lawrence e Seaborg/ /McMillan/Libby. Em química, a componente tácita é ocasionalmente mais notória do que em física, mas é no campo da medicina que o papel do conhecimento tácito surge de forma mais ampla e constante: práticas cirúrgicas, radiografias e outras imagiologias, meios não-invasivos de diagnóstico, etc.. Compreende-se que tenha sido um médico, que veio a ser químicofísico, a reconhecer estas componentes tácitas como conhecimento e não apenas como "artes". Aliás o tomá-las como "meras artes", mais acentua a separação entre ciências e humanidades. E mesmo nestas condições optimizadas, não foi fácil para Polanyi a conquista de um tal entendimento. 
Como decorre do que temos vindo a apresentar, nós professores carecemos de recuperar a dimensão humana do conhecimento e, nomeadamente, do conhecimento científico, ou por outras palavras, lançar pontes para uma humanização da ciência. Um campo privilegiado é, no entender de Michael Polanyi, o da descoberta científica, o verdadeiro paradigma da aquisição do conhecimento. Nela os conceitos, os cientistas e as estruturas sociológicas da ciência estão sujeitos a enormes tensões. Quando reflectidos através de um apropriado sistema filosófico, como o da «filosofia heurística» que temos vindo a apresentar, recolhemos as tais lições de humanização que procuramos. É que a ciência está assente em sistemas de convicções nos quais explicações e teorias contrárias aos paradigmas vigentes são rejeitadas ou ignoradas, mesmo que correctas e provadas. Foi isto que procurámos fazer em "Nos Bastidores da Ciência. 20 Anos Depois" [41]. O que a obra vos conta são diversas histórias, entrançadas com a história de uma controvérsia científica, que essencialmente se passou durante estes 20 anos, muito nos bastidores da ciência. O fulcro do confronto dá-se entre ISM (interaction- and intersecting-state model) - uma teoria sobre velocidades de reacções químicas desenvolvida nos começos de 1986 por mim e pelos meus colaboradores em Coimbra - com a Teoria de Marcus, no campo da transferência de electrões, que havia recebido o Prémio Nobel da Química em 1992. De novo a química se revela uma ciência muito apropriada para tais desideratos.

A TCT rejeita a existência de uma qualquer descontinuidade entre as ciências da natureza e as humanidades. Em palavras dos seus biógrafos «Polanyi opposed envisoning the humanities, especially the discipline of history, as radically different from the natural sciences. Instead, he believed that the many levels of reality revealed by the tacit knowing provide for a continuum of disciplines from physics and chemistry through biology to the behavioral sciences and the humanities" [42]. As duas culturas diferem entre si no grau de participação pessoal; maior no caso das ciências sociais e da história e menor na matemática ou na física. Porém, não há descontinuidade, porque em todas há sempre a participação pessoal do investigador, que não se consegue extirpar nem é desejável procurar fazê-lo [43]. Em suma, o conhecimento pessoal é uma fusão entre o pessoal e o universal, uma reivindicação para estabelecer contactos com uma realidade exterior à própria pessoa.

«O acordo tácito e as paixões intelectuais, a partilha de uma língua e de uma herança cultural, a filiação a uma comunidade que pensa do mesmo modo: tais são os impulsos que moldam a nossa visão da natureza das coisas em que nos apoiamos para dominarmos as próprias coisas. Qualquer inteligência, mesmo crítica e original, tem de operar dentro de um tal quadro fiduciário» [44]. Para logo de seguida afirmar, "se bem que a aceitação deste enquadramento seja a condição para se construir alguma forma de conhecimento, esta matriz não possui auto-evidência» [45].

Não obstante, por aplicação de «análise de agrupamentos» (cluster analysis) à importância relativa das áreas científicas em diferentes países europeus, encontramos semelhanças e diferenças que, quando representadas mediante dendrogramas, conseguem tornar evidentes certas marcas culturais, geográficas, linguísticas e históricas, na ciência europeia, em consonância com a ausência de descontinuidade entre ciências da natureza e ciências do homem e da sociedade [46].

No domínio das artes requer-se um esqueleto, um certo padrão formal, como a rima ou a métrica num poema, a tela numa pintura, um contexto litúrgico ou ritual em cerimónias religiosas. É este esqueleto artificial que destaca estes trabalhos artísticos e actos religiosos dos ambientes do quotidiano e que permite a apreciação estética. Devido a este distanciamento e cesura do quotidiano, as artes, o religioso, os mitos possuem significações que são trans-naturais, em contraste com as percepções correntes e em ciência [47].

Não necessitamos de recrear a visão imaginativa de Newton a entender e aplicar as suas leis do movimento à gravitação, ou a intuição que levou Bell a inventar o telefone; mas quando apreciamos uma obra de arte de um Miguel Angelo ou uma sinfonia de Beethoven temos de exercer muito da nossa imaginação e emoção estética [48].

Polanyi coloca ainda outra distinção de grau entre ciências e humanidades. Quando empregamos uma palavra para designar um objecto, não prestamos especial atenção à componente subsidiária, a palavra. A componente focal, o objecto, é que tem um interesse intrínseco neste caso. Trata-se do caso de uma indicação. Já se pensarmos na bandeira de um país, não prestamos grande atenção à componente focal, o pano da bandeira, mas sim às componentes subsidiárias, 0 país e os seus cidadãos. Trata-se do caso de uma simbolização. No caso de uma metáfora é o simbólico que quase esgota toda a nossa atenção. Tudo são distinções entre ciências e humanidades, mas que não estabelecem um fosso entre estes dois grandes campos de actividade intelectual [49].

Gulick vai no mesmo caminho ao referir que na apreciação de uma qualquer obra de arte, o artista ou o crítico tem de apreciá-la segundo uma perspectiva estética, na qual confronta as emoções pessoais que a obra lhe suscita (a "voz" colectiva dos aspectos subsidiários que reconhece de forma tácita), com a concepção de significado e propósito da obra em si, como objecto ou monumento de arte, segundo padrões de maior universalidade [50]. Padrões tais como a melancolia e a nostalgia em poesia do romantismo, a impressão visual na pintura impressionista, o contraste de cores no fauvismo de Matisse, uma intenção plástica de emoção teatral na arquitectura do barroco, etc., etc.

\section{A CIÊNCIA COMO ARTE}

Já referimos no início deste trabalho, que por vezes retiramos vantagens em «pensar a ciência como arte». O aforismo "All art is caricature», também é válido em ciência, pois as teorias e os modelos científicos mais não 
são do que caricaturas da realidade, do mundo e dos seus fenómenos. Como é que um cartoonista produz uma caricatura de uma face famosa como a de Einstein ou de Pavarotti? De um modo tácito e inconsciente, faz uma "média" de todas as faces e subtrai da média a face a desenhar, amplificando e enfatizando seguidamente as diferenças [51]. Tal pode dizer-nos mais sob o ponto de vista emocional do que uma fotografia a cores do próprio, apesar desta conter mais informação do que a caricatura.

Nos processos de aprendizagem animal, consegue-se que um rato discrimine um rectângulo (digamos $3 \times 2$ ) de um quadrado, graças a uma recompensa sempre que seja bem sucedido na tarefa. Paradoxalmente, o que se verifica é que o rato passa a responder ainda melhor a um rectângulo mais acentuado (digamos $4 \times 1$ ) do que ao prototipo utilizado no treino. Tal mostra que este animal não "aprendeu" o prototipo, mas sim a regra da rectangularidade, num denominado peak-shift effect [52].

De algum modo, dado os limitados recursos dedicados à atenção no cérebro, bem como aos limites espaciais nos circuitos neuronais para lidarem com diferentes modos de representação competitivos, invocam Ramachandran e Hirstein que a cada etapa do processamento de informação se gera um: «Olha, atenção! Há aqui uma pista para qualquer coisa que potencialmente pode ser um sinal proveniente de um objecto». Tal vai activar o sistema límbico, e acaba por chamar a nossa atenção para aquela região do cérebro que foi activada ou para aquele aspecto que activou uma região do sistema límbico, facilitando o processamento subsequente daquelas regiões e aspectos [53].

Outro aspecto essencial do reconhecimento de padrões diz respeito à percepção visual e à colagem (binding) do padrão. Consideremos uma imagem com uma série de manchas um pouco difusas de folhas de árvore e de um dálmata a cheirar algumas dessas folhas caídas no chão. Inicialmente vemos uma salganhada caótica de borrões. O número de possibilidades de agrupamento de tais borrões é infinito, mas uma vez que consigamos discernir o cão, nunca mais esta colagem de borrões se desfaz na nossa mente quando olhamos para a imagem. E quando discernismo uma tal colagem com o dálmata, emerge um aah! interior — uma emoção estética.

Também em ciência surgem por vezes tais emoções aquando de alguma descoberta ou do develar de uma relação escondida. Eu mesmo relatei uma tal experiência pessoal a respeito de ISM [54]. É que o ponto crucial na noção de realismo no pensamento polanyiano não assenta na quantidade de manifestações apresentadas por uma dada entidade, mas no carácter de surpresa de que essas manifestações se revestem. Nomeadamente, manifestações de beleza, harmonia e coerência intelectuais são indicativos de um contacto com a realidade.

O cérebro dos primatas tem mais de uma dúzia de áreas visuais, dedicadas a diferentes tipos de visão: movimento, cor, profundidade, forma, etc.. Tais áreas estão possivelmente aptas a extrair correlações em espaços multidimensionais. Num mapa topográfico normal, as regiões próximas no espaço físico ficam também juntas no nosso cérebro. Mas em mapas não-topográficos, como um mapa de cores que funciona à base de comprimentos de onda, pontos com a mesma cor, mesmo que fisicamente distantes uns dos outros, são agrupados na mesma região cerebral para a visão de cores. É esta proximidade em diferentes dimensões que parece estar envolvida na colagem do padrão do dalmata [55].

Em arte, tal como na ciência, além do peak-shift effect e do binding carece-se de isolar uma única modalidade visual, antes de tacitamente amplificarmos o sinal numa tal modalidade. Bem sabemos que em arte um mero contorno ou um esquisso podem ser esteticamente muito mais apelativos de que uma fotografia muito mais rica em informação. É que em arte, a informação redundante acaba por distrair os nossos limitados recursos mentais dedicados à atenção dos atributos relevantes de um dado objecto. O mesmo acontece em ciência, pelo que temos de recorrer, por vezes, a caricaturas de caricaturas para encontrar o essencial.

Um princípio da psicologia da forma (psicologia Gestalt [56]) a que Michael Polanyi recorre com frequência na TCT: «The particulars of a pattern or a tune must be apprehended jointly, for if you observe the particulars separately they form no pattern or tune» [57]. Ou por outras palavras: «The perception of wholes can be destroyed by persistent emphasis on the constituent elements, which releases them from the band which the mind instinctively clasps around them» [58]. Recorremos ao mesmo tipo de princípio cautelar - «a percepção de um todo pode ser destruída por uma demasiada ênfase nos elementos que o constituem» para alcançar um entendimento químico no contexto do formalismo ISM, por contraposição a uma visão electrostática da química computacional [59].

Outro princípio importante em arte é o do recurso ao contraste para extrair informação em ordem a uma «colagem» correcta [60]. É que a informação no sentido que Ihe conferiu Shannon, existe preferencialmente em bordas e em zonas de transição do que em regiões de homogeneidade, pelo que essas regiões são mais interessantes e devem merecer em especial a nossa atenção. Os artistas exploram estímulos em contrastes de cores, de texturas, de luminosidade, etc.. Os cientistas encontram tais estímulos em condições extremas, nas fronteiras, em anomalias, previsões arrojadas, etc.. Apelando de novo à minha experiência pessoal, encontrareis muitos destes estímulos na controvérsia científica de ISM com a Teoria de Marcus para reacções de transferência de electrão [61].

Em suma, na Teoria do Conhecimento Tácito encontramos uma maior riqueza conceptual e uma outra solidez de "teoria de pensamento" do que em outras filosofias das ciências que marcaram a visão contemporânea da Ciência. E encontramos conceitos novos, como o do conhecimento tácito, racionalizadores de perspectivas aparentemente mais obscuras do comportamento dos cientistas, amiudadas 
vezes como artesãos de ciência. A TCT é mais profunda na essência dos nossos modos de conhecer e de construir o conhecimento como seres vivos, indo mesmo para além do modo de ver em paralelo a «ciência como arte», pois se situa nos campos do epistemológico e do ontológico.

Trata-se de um sólido fundamento para lidar com a complexidade do conhecimento científico nas sociedades hodiernas, abarcando as relações entre ciência e religião, que se revestem de particular acuidade nos dias de hoje, e diria ainda no diálogo inter-religioso, pois todas as religiões partilham em comum o tácito do Sagrado, o que na busca do Mistério não está cerzido com a linguagem humana. Nós mesmos temos cultivado, em língua portuguesa, alguma da primeira vertente desta problemática na linha da TCT de Polanyi [62]. Em língua inglesa merece destaque a obra de Esther Meek [63]. O químico teórico C. A. Coulson, desde cedo desejou que Personal Knowledge se convertessse num "germ of a new Christian apologetic, relevant for to the twentieth century» [64]. O alerta para este tema não me parece desapropriado, dado toda esta temática me ter sido suscitada num terra de culto, como é hoje Fátima.

\section{Agradecimentos}

Agradeço aos meus colegas Carlos Romão e Ana Margarida Martins todo o apoio e contributos na materialização deste tributo ao seu pai e avô-científico. A minha gratidão vai igualmente para o meu colega Correia Cardoso pelas reflexões que produziu sobre uma versão preliminar deste trabalho e que me suscitaram outras reflexões e aprimoramentos.

\section{REFERÊNCIAS}

[1] D. Costa Pereira, "Nova Educação na Nova Ciência para a Nova Sociedade. Fundamentos de uma Pedagogia Científica Contemporânea", Vol. 1, Editora da Universidade do Porto, Porto, 2007. O autor aborda nas págs.
288 e 329 , num contexto distinto, e a propósito do modo-3 de conhecimento, a «importância do conhecimento tácito das empresas japonesas».

[2] W. B. Gulick, "Signals, Schemas, Subsidiaries, and Skills: Articulating the Inarticulate", Tradition \& Discovery 33(3) (2006-2007) 44-62; pág. 44; disponível no site da Polanyi Society, http://www. missouriwestern.edu/orgs/polanyi/, que procura divulgar o pensamento filosófico deste cientista.

[3] Fernando Pessoa, em "Apreciações Literárias. Bosquejos e Esquemas Críticos", Editora Estante, Aveiro, 1990, pág. 16.

[4] Ernst Peter Fischer, "Die andere Bildung. Was man von Naturwissenschaten wissen sollte", Ullstein, Berlin, 2003, pág 434; citado por Peter Hanenberg, "Sobre a utilidade das teorias cognitivas na aplicação à literatura e à historiografia", Cadernos do CIEG (Centro Interuniversitário de Estudos Germanísticos) 16 (2005) 9-22.

[5] M. Polanyi, "Personal Knowledge. Towards a Post-critical Philosophy" (PK), Routledge \& Kegan Paul, Londres, 1958, ed. compulsada 1969.

[6] M. Polanyi, "The Tacit Dimension. The Terry Lectures”, Yale University, 1962. London: Routledge \& Kegan Paul, Garden City, NY: Doubleday, 1966.

[7] W. Taussig Scott e M. X. Moleski (S.J.), "Michael Polanyi. Scientist and Philosopher", Oxford Univ. Press, New York, 2005, págs. 187, 188.

[8] S. J. Formosinho, "Pensar e Olhar a Ciência", Oração de Sapiência, Universidade de Coimbra, 19 de Setembro de 2007; http://antigos-estudantes.uc.pt/ media_uc/discursos/070919DO.pdf; acesso em 8 de Dezembro de 2007.

[9] S. Formosinho, "Nos Bastidores da Ciência. 20 Anos Depois", Imprensa da Universidade de Coimbra, Coimbra, 2007, págs. 265, 266; site da Imprensa da Universidade de Coimbra http://www.imp.uc.pt/livraria/?lang=PT.

[10] Gulick, ob. cit., pág. 44. Em meu entender, muito possivelmente o conhecimento tácito não é inteiramente computorizável.

[11] M. Polanyi, "Knowing and Being" (KB), Routledge, London, 1969, pág. 144.

[12] Gulick, ob. cit., pág. 45.
[13] Polanyi, PK, ob. cit., pág. 88, 92.

[14] Polanyi, KB, ob. cit., pág. 124.

[15] Polanyi, KB, ob. cit., pág. 126.

[16] Gulick, ob. cit., pág. 45.

[17] Michael Polanyi, "The Value of the Inexact”, Tradition \& Discovery 18(3) (1992) 35-46.

[18] Blythe McVicker Clinchy, "Pursued by Polanyi, Tradition \& Discovery 34(1) (2007-2008) 54-67; pág. 55.

[19] Taussig Scott e Moleski, ob. cit., pág. 205.

[20]TaussigScotteMoleski, ob. cit., pág. 259.

[21] Clinchy, ob. cit., pág. 56.

[22] Zhenhua Yu, "Feminist epistemology in a Polanyian perspective", Tradition \& Discovery 34(1) (2007-2008) 49-53; pág. 50.

[23] Esther L. Meek, "Cultivating connected knowing in the classroom", Tradition \& Discovery 34(1) (2007-2008) 40-48; págs. $40,41$.

[24] Clinchy, ob. cit., pág. 57.

[25] R. W. Howard, "Concepts and Schemata: an Introduction", Cassell, Londres, 1987, pág. 176; Clinchy, ob. cit., pág. 51.

[26] Polanyi, PK, ob. cit., págs. 71-77; Gulick, ob. cit., pág. 51.

[27] Araminta Stone Johnston, "Theory, rationality, and relativism", Tradition \& Discovery 20(3) (1993-1994) 16-28; pág. 26.

[28] Polanyi, PK, ob. cit., pág. 300.

[29] Araminta Stone Johnston, ob. cit., pág. 25.

[30] Taussig Scott e Moleski, ob. cit., pág. 248.

[31] Gulick, ob. cit., pág. 48.

[32] M. Polanyi, "Science, Faith and Society", Oxford University Press, Oxford, 1946, pág. 46; Clinchy, ob. cit., pág. 59.

[33] Polanyi, KB, ob. cit., pág. 66; Clinchy, ob. cit., pág. 59 .

[34] Convém relembrar que a metodologia do falsificacionismo das teorias científicas de Popper assenta na objectividade de carácter impessoal da ciência e na infalibilidade do cientista.

[35] A. M. Davis, S. J. Teague e G. J. 
Kleywegt, "Application and Limitations of X-ray Crystallographic Data in Structure-Based Ligand and Drug Design", Angew. Chem. Int. Ed. 42 (2003) 2718-2736; agradeço ao meu colega Prof. Hugh Burrows a indicação desta referência.

[36] Zhenhua Yu, "Tradition, authority and originality in a post-critical perspective", Tradition \& Discovery 32(3) (2005-2006) 40-56; pág. 43.

[37] Gulick, ob. cit., pág. 48.

[38] Ver, por exemplo, Costa Pereira, ob. cit., págs. 365-387.

[39] Polanyi, PK, ob. cit., pág. 227.

[40] Zhenhua Yu, "Tradition, authority and originality in a post-critical perspective", ob. cit. pág. 41.

[41] Formosinho, "Nos Bastidores da Ciência. 20 Anos Depois", ob. cit. .

[42]TaussigScotteMoleski, ob. cit., pág. 231.

[43] A. Sanders, "Science, Religion and Polanyi's Comprehensive Realism", Tradition \& Discovery 26(3) (1999-2000) 84-93; pág. 86

[44] Polanyi, PK, ob. cit., pág. 266.

[45] Itálico nosso.

[46] Formosinho, Oração de Sapiência.

[47] Yu Zhenhua. "Two Cultures Revisited:
Michael Polanyi on the Continuity Between the Natural Sciences and the Study of Man", Tradition \& Discovery 28(3) (2001-02) 6-19; págs. 13, 14.

[48] Yu Zhenhua. "Two Cultures Revisited", ob. cit.; pág. 13.

[49] Yu Zhenhua. "Two Cultures Revisited", ob. cit.; pág. 14.

[50] Gulick, ob. cit., pág. 55.

[51] V.S. Ramachandran e William Hirstein, "The Science of Art. A Neurological Theory of Aesthetic Experience", Journal of Consciousness Studies 6(6-7) (1999) 15-51.

[52] Ramachandran e Hirstein, ob. cit., pág. 18.

[53] Ramachandran e Hirstein, ob. cit., pág. 23.

[54] Formosinho, "Nos Bastidores da Ciência. 20 Anos Depois", ob. cit., págs. 164-169.

[55] Ramachandran e Hirstein, ob. cit., pág. 22.

[56] Palavra de origem alemã que «significa uma integração de partes em oposição à soma do "todo"».

[57] Polanyi, PK, ob. cit., pág. 57.

[58] Taussig Scott e Moleski, ob. cit., pág. 188.

[59] Sebastião Formosinho, "Nos Basti- dores da Ciência. 20 Anos Depois", ob. cit., págs. 121-138; Luís Arnaut, Sebastião Formosinho e Hugh Burrows, "Chemical Kinetics. From Molecular Structure to Chemical Reactivity", Elsevier, Amsterdam, 2007, especialmente caps. 6 e 7, págs. 295-305 e 379-383; L. G. Arnaut e S. J. Formosinho, "Understanding Chemical Reactivity: The Case for Atom, Proton and Methyl Transfers", Chem. Eur. J., submetido a publicação.

[60] Ramachandran e Hirstein, ob. cit. pág. 25.

[61] Formosinho, "Nos Bastidores da Ciência. 20 Anos Depois", ob. cit., cap. 6 e págs. 399-405.

[62] S. J. Formosinho e J. Oliveira Branco, "O Deus que não temos", Editorial Bizâncio, em publicação; S. J. Formosinho, "O Conhecimento Tácito em Michael Polanyi. Uma terapia epistemológica para as relações entre a ciência e a religião", Estudos, Nova Série, CADC.

[63] E. L. Meek, "Longing to Know. The philosophy of knowledge for ordinary people", Brazos Press, Grand Rapids, MI, 2004

[64] Taussig Scott e Moleski, ob. cit., pág. 231

\section{Actualidades Científicas}

\section{Pequeno e Sensível}

Um protótipo de um pequeno sensor que pode detectar com rapidez quantidades diminutas de gases perigosos, nomeadamente químicos industriais tóxicos e agentes químicos de aplicação bélica, está a ser desenvolvido por investigadores do Massachusetts Institute of Technology. Este aparelho combina cromatografia gasosa e espectrometria de massa em sistemas com o tamanho de um rato de computador.

A miniaturização dos detectores de gases torna a sua aplicação muito mais fácil, já que possibilita a sua instalação generalizada através de edifícios ou de zonas abertas. A redução de tamanho destes aparelhos também limita o seu consumo energético e potencia a sua sensibilidade na detecção de concentrações muito baixas de gases. As versões comuns de equipamentos GC-MS portáteis são de resposta lenta (15 minutos), volume considerável e consumo energético elevado (10000 J). O novo modelo de sensor é significativamente mais pequeno, consome muito menos energia (aproximadamente $4 \mathrm{~J}$ ) e produz resultados em 4 segundos.

A equipa de investigação, constituída por Akintunde Ibitayo Akinwande, professor de Ciência de Computadores e Engenharia Electrotécnica e Luis Velasquez-Garcia, espera reduzir ainda mais o tamanho do detector, possivelmente até à escala de uma caixa de fósforos.

Após a fase de desenvolvimento, que se espera durar ainda mais dois anos, este aparelho pode ser utilizado para a protecção de águas de abastecimento, diagnósticos médicos ou para a detecção de gases perigosos em ambientes industriais ou urbanos. (adaptado de webzine Reactive Reports 72, 2008). 

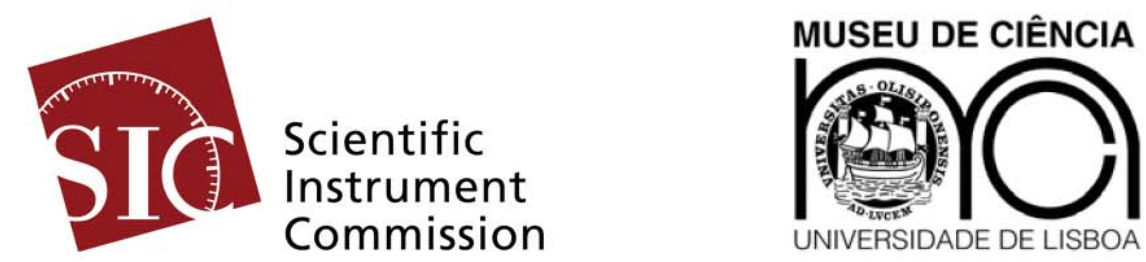

\title{
XXVII Simpósio da Scientific Instrument Commission
}

\author{
Museu de Ciência \\ Universidade de Lisboa
}

16-21 Setembro 2008
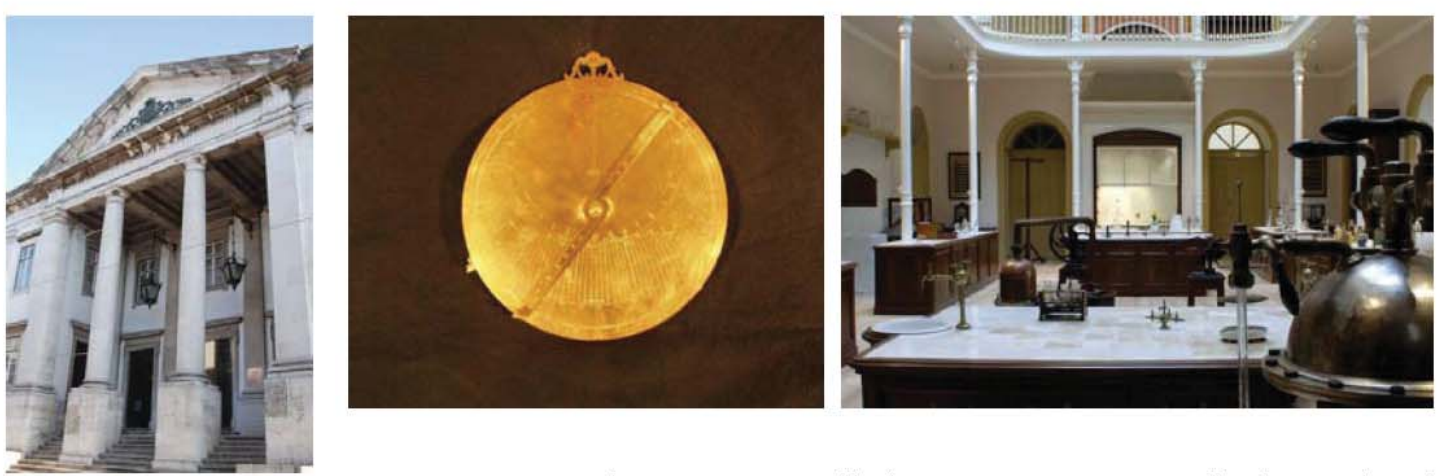

(Fotos esq. para direita: J. Sotomayor, A. Cabral \& P. Cintra)

Este ano, o Museu de Ciência da Universidade de Lisboa vai acolher o XXVII

Simpósio da Scientific Instrument Commission (SIC2oo8). A

Scientific Instrument Commission faz parte da União Internacional de História e Filosofia da Ciência (IUHPS) e tem como principais objectivos o estudo, documentação, preservação e valorização das colecções de instrumentos científicos, bem como promover a sua utilização como fonte para a história da ciência.

O encontro SIC2008 vai reunir em Lisboa cerca de 120 dos mais importantes especialistas mundiais em instrumentos científicos e também prestigiados historiadores da ciência. É a primeira vez que uma reunião com este tema e esta importância se realiza em Portugal.

O Museu de Ciência da Universidade de Lisboa pretende, com este encontro, para além de aprofundar e consolidar o nosso conhecimento sobre instrumentos, divulgar o património científico português junto da comunidade científica internacional e também promover estudos de instrumentos e cultura material junto de jovens historiadores da ciência portugueses.

O Programa vai incluir visitas às mais importantes colecções de instrumentos científicos em Portugal:

- Museu de Ciência da Universidade de Lisboa, incluindo o recentemente inaugurado Laboratorio Chimico da Escola Politécnica

- Museu de Marinha, Lisboa 
- Museu de Metrologia do Instituto Português de Qualidade, Caparica

- Museu de Farmácia, Lisboa

- Observatório Astronómico da Ajuda, Lisboa

- Colecção de Instrumentos Científicos do Instituto Superior Técnico, Lisboa

- Gabinete de Física da Escola Secundária Passos Manuel, Lisboa

- Museu da Academia das Ciências de Lisboa

- Museu da Ciência da Universidade de Coimbra

- Museu de Física da Universidade de Coimbra

- Colecção de Astronomia da Universidade de Coimbra

- Museu de Ciência da Universidade do Porto

- Museu da Faculdade de Engenharia, Universidade do Porto

- Museu Parada Leitão, Instituto Superior de Engenharia, Porto

Para mais informações e inscrições:

http://chcul.fc.ul.pt/sic20o8

sic2008@museus.ul.pt

SIC20o8 é organizado em colaboração com o Centro de História da Ciência da Universidade de Lisboa.
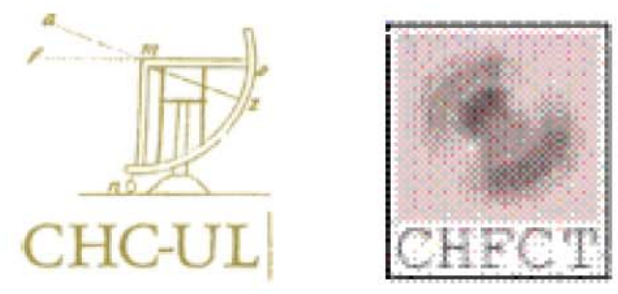

SIC20o8 é apoiado por:
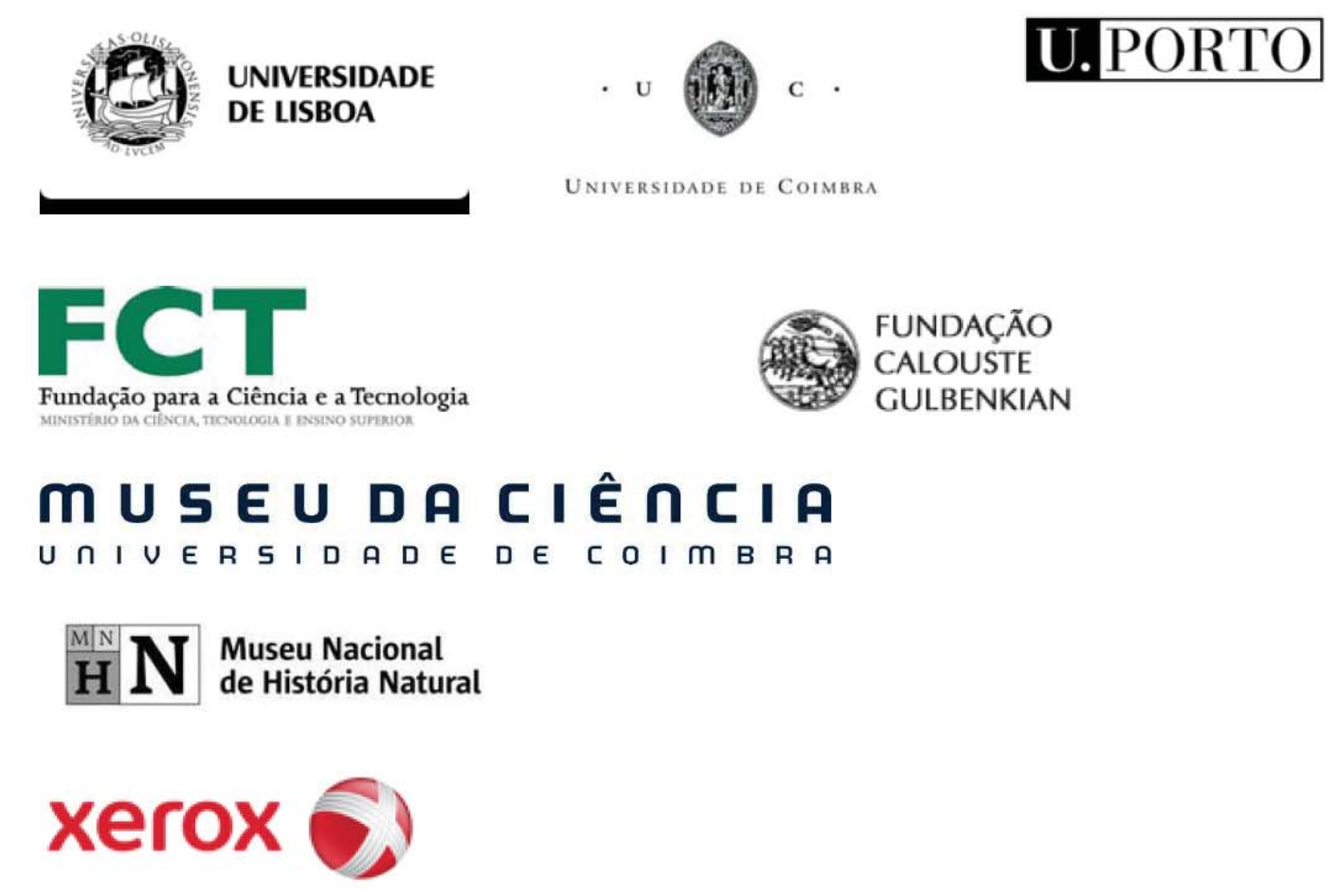